\title{
Identification of Potential Lead Molecules against Dibenzo[a,l]pyrene-induced Mammary Cancer through Targeting Cytochrome P450 1A1, 1A2, and 1B1 Isozymes
}

\author{
Azeem Mohd Umar ${ }^{1}{ }^{(D)}$, Akhtar Salman ${ }^{2}$ (D), Siddiqui Mohammed Haris ${ }^{3}$ (D), Khan Mohammad Kalim \\ Ahmad 4,*iD \\ 1 Department of Bioengineering, Integral University, Lucknow-226026, Uttar Pradesh, India; umarazeem@iul.ac.in \\ (A.M.U.); \\ 2 Department of Bioengineering, Integral University, Lucknow-226026, Uttar Pradesh, India; sakhtar@iul.ac.in (A.S.); \\ 3 Department of Bioengineering, Integral University, Lucknow-226026, Uttar Pradesh, India; \\ mohdharis.siddiqui@gmail.com (S.M.H.); \\ 4 Department of Bioengineering, Integral University, Lucknow-226026, Uttar Pradesh, India; mkakhan@iul.ac.in \\ (K.M.K.A.); \\ * Correspondence: mkakhan@iul.ac.in (K.M.K.A.);
}

Scopus Author ID 57193235237

Received: 20.03.2021; Revised: 18.04.2021; Accepted: 20.04.2021; Published: 26.04.2021

\begin{abstract}
Cytochrome P450 (CYP) isozymes are promising therapeutic targets against dibenzo $[a, l]$ pyrene-induced mammary cancer. Current research aims to identify potential lead molecules against mammary cancer targetting CYP1A1, 1A2, and 1B1 using ligand-based virtual screening (LBVS), molecular interactions, MD simulation, and in vitro studies. The LBVS predicted 30,500 hits, which were reduced to 400 when sifted through Lipinski RO5, and ADMET parameters. These 400 compounds were carried forward for molecular docking with the selected CYP isozymes. The ligand CHEMBL224064 (CHEMBL1), CHEMBL2420083 (CHEMBL2), and CHEMBL61745 (CHEMBL3) depicted stronger binding respectively in CYP1A1 (-10-52 kcal/mol), 1A2 (-10.82 $\mathrm{kcal} / \mathrm{mol})$, and $1 \mathrm{~B} 1(-10.78 \mathrm{kcal} / \mathrm{mol})$ in comparison to known inhibitor alpha-naphthoflavone (ANF) $(-9.13 \mathrm{kcal} / \mathrm{mol},-9.66 \mathrm{kcal} / \mathrm{mole}$, and $-9.67 \mathrm{kcal} / \mathrm{mol}$ respectively in CYP1A1, 1A2, and 1B1). These compounds were found stable with their respective targets during MD studies of 50 ns duration. Furthermore, (3-(4, 5-dimethylthiazolyl-2)-2, 5-diphenyltetrazolium bromide) (MTT) and enzyme inhibition assay elucidated and validated the inhibitory potential of identified ligands against mammary carcinomas. The study reveals a significant understanding of PAH-mediated mammary cancer and its prevention.
\end{abstract}

Keywords: cytochrome P450; dibenzo[ $a, l]$ pyrene; LBVS; molecular docking; MD simulation.

(C) 2021 by the authors. This article is an open-access article distributed under the terms and conditions of the Creative Commons Attribution (CC BY) license (https://creativecommons.org/licenses/by/4.0/).

\section{Introduction}

Dibenzo[a,l]pyrene (DBP) is one of the deadly pro-carcinogenic environmental polycyclic aromatic hydrocarbons (PAHs) produced by partial oxidation of woods, charcoals, plastic wares, fossil fuels, and tobacco products. It consists of six-fused benzene rings and structurally showing two clefts, respectively known as a fjord- and bay-regions. The former comparatively produces more carcinogenic intermediates [1-4]. Biotransformation of DBP undergoes three consecutive steps. In first step cytochrome P450 (CYP) isozymes especially CYP1A1, 1A2, and 1B1 metabolize DBP into dibenzo[a,l]pyrene-11,12-epoxide (DBPE). The 
second step deals with the microsomal epoxide hydrolase $(\mathrm{mEH})$, which converts DBPE into the dibenzo[a,l]pyrene-11,12-dihydrodiol (DBPD). In the final step again CYP isozymes transforms DBPD to its ultimate carcinogenic metabolites dibenzo[a,l]pyrene-11,12dihydrodiol-13,14-epoxide (DBPDE) [5,6]. The most potent metabolite DBPDE known among other PAHs reported to date exerts more breast cancer-causing propensities than other human cancers $[7,8]$.

CYPs have been gaining significant attention from scientists worldwide because of their diverse role in the metabolism of various chemicals, pollutants, food contaminants, drugs, and other xenobiotics, facilitating phase II metabolizing enzymes in their detoxification, thereby preventing undesired effect on human health. However, most PAHs yield reactive carcinogenic metabolites mitigating carcinogenic phenomena upon bioactivation through CYPs [8-11]. More than $70 \%$ biotransformation of PAHs undergo through CYP1A1, 1A2, 1B1, 2A6, 2E1, and $3 \mathrm{~A} 4$ [12].

CYPs are heme-containing monooxygenase enzymes representing more than 13,000 and 400 genes under superfamily and family heads across all the kingdoms known. In humans, about 57 genes and 58 pseudogenes related to various families (18) and subfamilies (44) have been reported [9]. CYPs can be categorized in many ways. CYPs play a role in detoxification of various chemical compounds, endogenous substance biosynthesis, membrane-attached as in higher organisms, and soluble types lower organisms. CYPs of higher organisms found in the endoplasmic reticulum (ER) felicitates via the flavin adenine dinucleotide (FAD) and flavin mononucleotide $(\mathrm{FMN})$ reductase systems. The electron transfer process in prokaryotes and mitochondrial CYPs succeeds through FAD reductase and iron-sulfur cascaded systems. CYPs performing multiple unrelated functions, e.g., biosynthesis of endogenous compounds, are referred to as moonlighting, while those playing a role in xenobiotic metabolism are known as non-moonlighting enzymes [8,9]. (p/CIP), and general transcription factors (GTFs) succeed through the interaction of TATA-binding protein (TBP) and RNA polymerase II inducing CYPs enzymes, which later metabolize DBP into its most hazardous carcinogenic intermediate DBPDE $[9,13,14]$.

Bioactivation of DBP occurs through coupling with the aryl hydrocarbon receptor (AhR), as happens in most PAHs, including the prototype PAH benzo[a]pyrene (BP). Upon DBP binding, the AhR detaches from its complex regulating and activating partners viz., aryl hydrocarbon receptor-interacting protein (AIP), heat shock protein 90 (Hsp90), and p23 (coactivator of Hsp90/70- chaperone system) and moves to the nucleus. The DBP-AhR complex binds with AhR nuclear translocator (ARNT). The DBP-AhR-ARNT complex activates through the phosphorylation of tyrosine amino acids at the C-terminus of AhR. Further, AhR-ARNT identifies xenobiotic response elements (XREs) on their respective CYPs promoter sites to modulate their genes. The genes for CYP1A1, 1A2, 1B1 enzymes mitigate through the molecular interaction of various coactivators and transcription-regulating factors viz., specificity protein 1 (Sp1), p300, co-integrator-associated protein

The study aims to inhibit CYP1A1, 1A2, and 1B1 by novel lead molecules, thereby preventing carcinogenic DBPDE -induced mammary cancer. Alpha-naphthoflavone (ANF), a known inhibitor of selected CYPs, was used as a template to find out potential lead molecules using integrated computational and bioinformatics approaches viz., high-throughput ligandbased virtual screening (LBVS), drug-likeness filtration, docking studies, and MD simulations (MDS). Post docking analysis of top hits, dynamics simulation, and their comparison with known inhibitor ANF yield one of the best lead molecules, succeeded through $(3-(4,5-$ 
dimethylthiazolyl-2)-2,5-diphenyltetrazolium bromide) (MTT) and enzyme inhibition assays. The study's findings uncover substantial mechanistic insight into the targeted therapy and prevention of PAH-induced mammary malignancies.

\section{Materials and Methods}

\subsection{CYP isozymes $3 D$ structure retrieval.}

The 3D crystal structure of CYP1A1 (4I8V), CYP1A2 (2HI4), and CYP1B1 (3PM0) complexed with ANF (CID: 11790) retrieved from research collaboratory for structural bioinformatics (RCSB) protein data bank (PDB) (https://www.rcsb.org/). ANF ligand truncated from the complex and apoprotein. The heme group considered making input files compatible for molecular interactions via truncating unwanted heteroatoms, ions, and molecules. The 3D coordinates of co-complexed ANF carried forward to study identified new chemical molecules. The relevant force field and energy optimization algorithm was employed to get proteins energetically minimized and optimized $[15,16]$.

\subsection{Virtual screening, ADMET analysis, and optimization.}

The hybrid technique, including molecular fingerprints, electro shape, spectrophores, shape IT, and align IT of LBVS approach searched various hits akin to the ANF molecule from publically available virtual databases viz., DrugBank, ChEMBL of EMBL-EBI, Chemical Entities of Biological Interest (ChEBI) database, GPCR-Ligand Association (GLASS) database, Human Metabolome Database (HMDB), and ZINC database [17,18]. The identified ligands were tested on Lipinski rule of five (RO5) (Molecular weight $<=500 \mathrm{Da}$; HBD $<=5$; HBA $<=10 ; \log \mathrm{P}<=5$ ). The RO5-satisfied ligands sifted through absorption, distribution, metabolism, elimination, and toxicity (ADMET) descriptors using the PreADMET server [1922]. Ligands succeeded ADMET descriptors were prepared for molecular interaction studies by assigning suitable energy minimization and optimization algorithms $[15,16]$.

\subsection{Molecular docking.}

Molecular interaction of selected ligands with CYP isozymes carried out using AutoDock Tools 4.0 (ADT) to get plausible binding mode. Four input files viz., pdbqt files of both ligand and protein, grid parameter file, and docking parameter file prepared to execute ADT. The grid was generated in such a way so that the ligand gets enough space to move within it freely. $62 \AA$ grid points separated each $\mathrm{x}, \mathrm{y}, \mathrm{z}$ axes, and spacing between the two grids set at $0.92 \AA$. Twenty runs for each ligand molecule employed in ADT. Post docking analysis depicted one of the ligand's best conformations with minimum binding energy $(\Delta \mathrm{G})$ carried forward for further molecular simulation analysis [23-25].

\subsection{MD simulation.}

MDS of 50 ns was employed to assess the flexibility and stability of CHEMBL1, 2, and 3 with CYP1A1, 1A2, and 1B1 enzyme respectively at $300 \mathrm{~K}$ using Groningen Machine For Chemical Simulations (GROMACS) package. The PRODRG server was used to generate topology and force-field parameter (ffp) files of all ligands. CYP1A1-ANF, CYP1A2-ANF, CYP1B1-ANF, CYP1A1-CHEMBL1, CYP1A2-CHEMBL2, and CYP1B1-CHEMBL3 complexes were absorbed in an orthorhombic water box at $10 \AA$ edge settings. The $\mathrm{Na}+$ and 
$\mathrm{Cl}$ - ions were added as a neutralizing agent and to preserve $0.15 \mathrm{M}$ physiologic concentration. The prepared system was energetically minimized at 2000 steps using the steepest descent algorithm. Two phases viz., NVT (constant number of particles, volume, and temperature) and NPT (constant number of particles, pressure, and temperature) ensembles were utilized to achieve the equilibration process. Post equilibration, the smooth particle-mesh-Ewald technique was used, followed by the execution of production phases of $50 \mathrm{~ns}$ duration. Analysis of all trajectories was accomplished through different GROMACS command utilities [26-28].

\subsection{Chemicals and reagents.}

Chemical compounds CHEMBL1 (6-iodo-4'-methoxyflavone), CHEMBL2 (3',4'dimethoxy-alpha-naphthoflavone), and CHEMBL3 (6-fluoroflavone) were obtained from Sigma-Aldrich St. Louis, MO. MCF-7 cell line from NCCS Pune India, PBS, penicillin, streptomycin, and MTT dye from HiMedia Laboratories India, ANF (7,8-benzoflavone), EMEM, FBS, and DMSO was procured from Sigma-Aldrich St. Louis, MO.

\subsection{Cell culture.}

The MCF-7 cells were maintained in EMEM supplemented with $10 \%$ FBS, $0.01 \mathrm{mg} / \mathrm{ml}$ insulin, and $1 \%$ penicillin/streptomycin.

\subsection{MTT cell viability assay.}

Using the MTT dye, colorimetric cell viability assays were conducted according to the manufacturer's protocol [29]. The mitochondrial dehydrogenases in viable cells reduced the tetrazolium ring of MTT, converting the yellow-colored MTT to purple formazan crystals. For each well, 5000 cells per were seeded in a 96-well plate, allowed to attach overnight, and then treated with ANF (0-100 $\mu \mathrm{M})$ or CHEMBL1, CHEMBL2, and CHEMBL3 (0-100 $\mu \mathrm{M})$ for 24 h. Cell viability was quantified at $540 \mathrm{~nm}$ using the BioTek plate reader (BioTek, Winooski, VT). Data were normalized to the vehicle control, DMSO, and collected from three independent experiments.

\subsection{In vitro CYP450 enzyme assay.}

For in vitro CYP450 enzyme assay, MCF-7 (1 x 106) were seeded in triplicates in black 96-well plates with transparent bottom. The test compounds at various concentrations (from 1$1000 \mathrm{nM}$ ) were added to the wells, followed by incubation at $37^{\circ} \mathrm{C}, 5 \% \mathrm{CO} 2$ for $30 \mathrm{~min}$. After incubation, a fluorogenic substrate 7-ER (7-Ethoxyresorufin) for CYP1A1, CYP1B1, and CEC (3-cyano-7-ethoxycoumarin) for CYP1A2 was added at five $\mu \mathrm{M}$ concentration to the wells, and contents mixed by shaking. The plate was read on a plate reader (Biotek, Synergy HT) for 60 min using suitable wavelengths for emission/excitation of the fluorescence products formed. Data were normalized to vehicle control, DMSO and collected from three independent experiments.

\subsection{Statistical analysis.}

Statistical analyses of the experimental data were performed using GraphPad Prism8, GraphPad Software, Inc., La Jolla, CA, USA. Either the two-sided t-test or one-way analysis 
of variance (ANOVA) was performed. The value $\mathrm{p}<0.01$ was considered significant. The flow chart of the adopted methodology is shown in Figure 1.

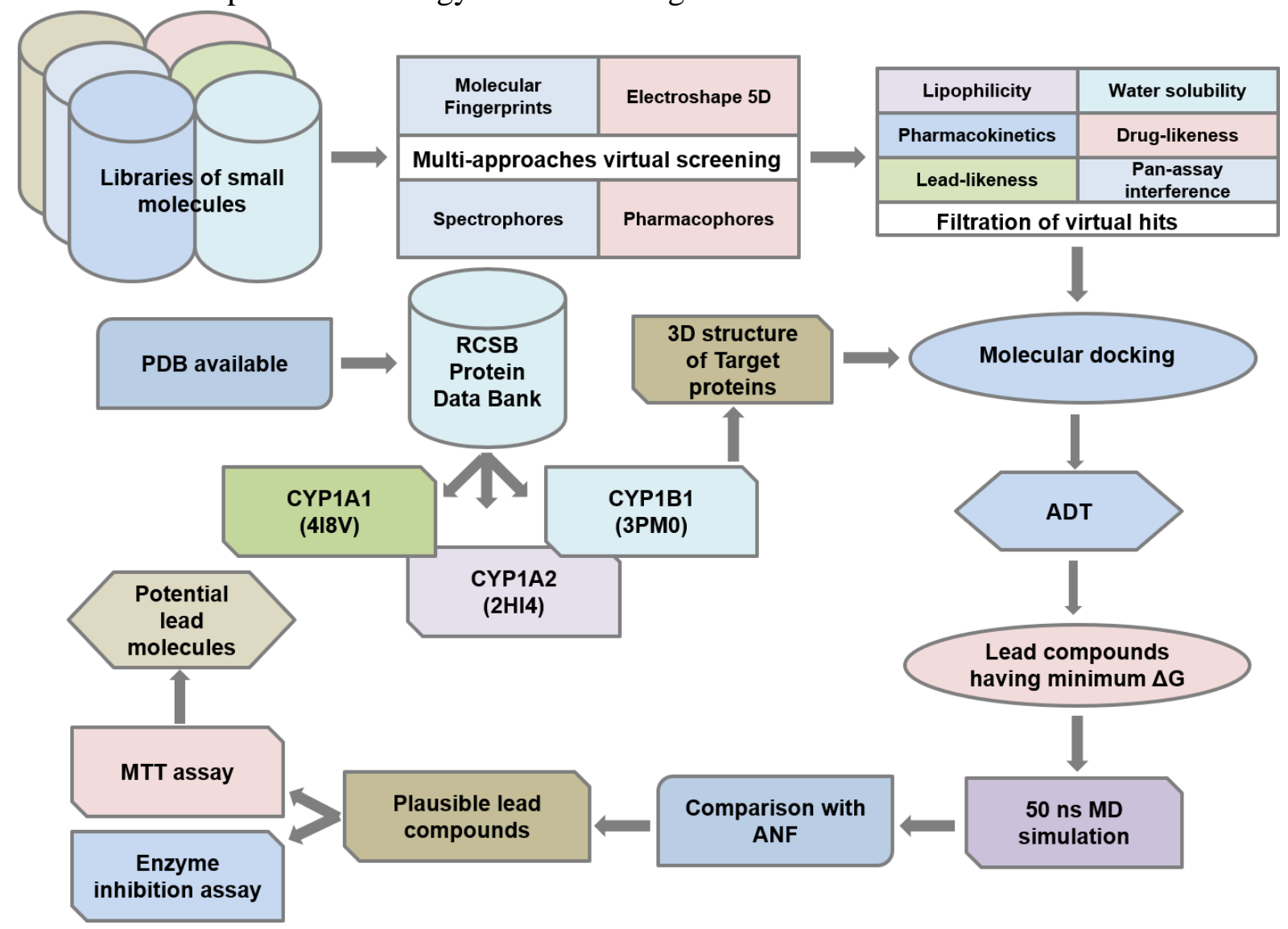

Figure 1. Flow chart of the adopted methodology.

\section{Results and Discussion}

\subsection{Drug-likeness and ADMET filtration.}

LBVS predicted 38,000 chemical hits out of 11,175,625 compounds of various virtual libraries of the SwissSimilarity database [18]. The RO5 filtration yielded 38,000 molecules, in which 400 molecules succeeded for HIA (human intestinal absorption; activity range: poorly0 20\%, moderate- 20 70\%, high- 70 100\%), BBB (blood-brain barrier; CNS active compounds $(+):>1$, CNS inactive compounds $(-)$ : $<1)$, PPB (plasma protein binding; chemicals strongly bound $>90 \%$, chemicals weakly bound $<90 \%$ ), MDCK (Madin-Darby canine kidney; lower-< 25, moderate-5 500, Higher- > 500) cell permeability, heterogeneous human epithelial Caco 2 cell permeability (lower-<4, moderate-4 70, higher-> 70), and mutagenicity and carcinogenicity rat and mouse models filtering non-toxic compounds as ADMET descriptors [30].

\subsection{Molecular docking and MD simulation.}

ADMET-satisfied compounds (400) akin to the ANF were subjected to dock with each CYP1A1, 1A2, and 1B1 predicting the most probable binding interactions. DBPD and ANF exhibited $\Delta \mathrm{G}$ values of $-7.12 \mathrm{kcal} / \mathrm{mol}$, and $-9.13 \mathrm{kcal} / \mathrm{mol}$ with CYP1A1, $-9.93 \mathrm{kcal} / \mathrm{mol}$, and $-9.66 \mathrm{kcal} / \mathrm{mol}$ with CYP1A2, $-10.08 \mathrm{kcal} / \mathrm{mol}$, $-9.67 \mathrm{kcal} / \mathrm{mol}$ with CYP1B1 respectively. Respectively, 83, 32, and 30 ligands comparatively depicted better interactions in terms of free 
energy of binding $\Delta \mathrm{G}(\mathrm{kcal} / \mathrm{mol})$ with CYP1A1, 1A2, and 1B1. Docking analysis of the top 10 ligands with each CYP isozyme is shown in Table 1-3.

Table 1. Molecular interactions of top 10 ligands, ANF, and DBPD with CYP1A1.

\begin{tabular}{c|l|c|l} 
S. No. & \multicolumn{1}{|c|}{ Ligands } & $\begin{array}{c}\text { ADT } \\
(\mathbf{( G )}\end{array}$ & \multicolumn{1}{|c}{ H-bonds } \\
\hline 01. & CHEMBL224064 & -10.52 & V387- HN...O12-LIG, R396-HE...O12-LIG \\
\hline 02. & CHEMBL2420082 & -09.99 & S87- HG...O-LIG \\
\hline 03. & CHEMBL2420083 & -10.46 & S87- HG...O-LIG \\
\hline 04. & CHEMBL2420094 & -10.35 & S87- HG...O-LIG \\
\hline 05. & CHEMBL2420096 & -10.04 & D285- OD1...H-LIG \\
\hline 06. & CHEMBL2420099 & -09.85 & S87- HG...O-LIG \\
\hline 07. & CHEMBL2431801 & -09.99 & S87- HG...O-LIG \\
\hline 08. & CHEMBL595616 & -10.28 & D285- OD1...H-LIG, I414- O...H-LIG \\
\hline 09. & CHEMBL595631 & -10.12 & W96- HE1...N-LIG, R420- HH11...N-LIG \\
\hline 10. & CHEMBL487213 & -09.87 & S87- HG...O-LIG \\
\hline 11. & ANF & -09.13 & Nil \\
\hline 12. & DBPD & -07.12 & V453-NH...O2-LIG
\end{tabular}

Table 2. Molecular interactions of top 10 ligands, ANF, and DBPD with CYP1A2.

\begin{tabular}{|c|c|c|c|}
\hline S. No. & Ligands & $\begin{array}{l}\text { ADT } \\
(\Delta \mathbf{G})\end{array}$ & H-bonds \\
\hline 01. & CHEMBL2420091 & -10.45 & R75-HH12...O-LIG \\
\hline 02. & CHEMBL2420094 & -10.58 & R219-HH12...O-LIG \\
\hline 03. & CHEMBL595616 & -10.73 & R423-O...H-LIG, D287-OD1 ...H-LIG \\
\hline 04. & CHEMBL2331821 & -10.42 & R75-HH12...O-LIG \\
\hline 05. & CHEMBL2420097 & -10.65 & R75-HH12...O-LIG \\
\hline 06. & CHEMBL2431801 & -10.48 & R75-HH12...O-LIG \\
\hline 07. & CHEMBL2420083 & -10.82 & G14-NH...O5-LIG \\
\hline 08. & CHEMBL2420100 & -10.76 & N157-HD2 ..O-LIG, R219-HH21_..O-LIG \\
\hline 09. & CHEMBL127267 & -10.57 & I353-H...N-LIG \\
\hline 10. & CHEMBL2431819 & -10.52 & I426-H...O-LIG \\
\hline 11. & ANF & -09.66 & R263-NH...O1-LIG \\
\hline 12. & DBPD & -09.93 & A102-O...H42-LIG \\
\hline
\end{tabular}

Table 3. Molecular interactions of top 10 ligands, ANF, and DBPD with CYP1B1.

\begin{tabular}{c|l|l|l} 
S. No. & \multicolumn{1}{|c|}{ Ligands } & $\begin{array}{c}\text { ADT } \\
(\mathbf{A G})\end{array}$ & \multicolumn{1}{|c}{ H-bonds } \\
\hline 01. & CHEMBL61745 & -10.81 & N353-HE2...F-LIG \\
\hline 02. & CHEMBL241830 & -10.44 & E162-H...O-LIG \\
\hline 03. & CHEMBL2420091 & -10.46 & R50-HH12...O2-LIG, I391-O...H-LIG \\
\hline 04. & CHEMBL2420099 & -10.51 & D262-OD2...H-LIG \\
\hline 05. & CHEMBL595616 & -10.55 & D262-OD2...H-LIG \\
\hline 06. & CHEMBL595631 & -10.68 & D262-OD2...H-LIG \\
\hline 07. & CHEMBL2420097 & -10.63 & D262-OD2...H-LIG \\
\hline 08. & CHEMBL2393069 & -10.78 & D255-OD2...H-LIG \\
\hline 09. & CHEMBL595407 & -10.58 & I391-O...H-LIG \\
\hline 10. & CHEMBL288714 & -10.55 & K383-HZ1... N-LIG \\
\hline 11. & ANF & -09.67 & R373-HH12...O2-LIG \\
\hline 12. & DBPD & -10.08 & W354-HE1...O2-LIG
\end{tabular}

Ligands tabulated showing a more significant binding affinity than the ANF and DBPD with their respective CYP1A1, 1A2, and 1B1 isozymes. Among all ligands, CHEMBL224064 (CHEMBL1) exhibited better interaction with CYP1A1 ( $\Delta \mathrm{G}$ : $-10.52 \mathrm{kcal} / \mathrm{mol})$ along with two H-bonds (V387-HN...O12-LIG, R396-HE...O12-LIG), supporting the stability of the docked molecule. The detailed molecular interactions of CHEMBL1, ANF, and DBPD with CYP1A1 are illustrated in Ligplot [31] (Figure 2). 


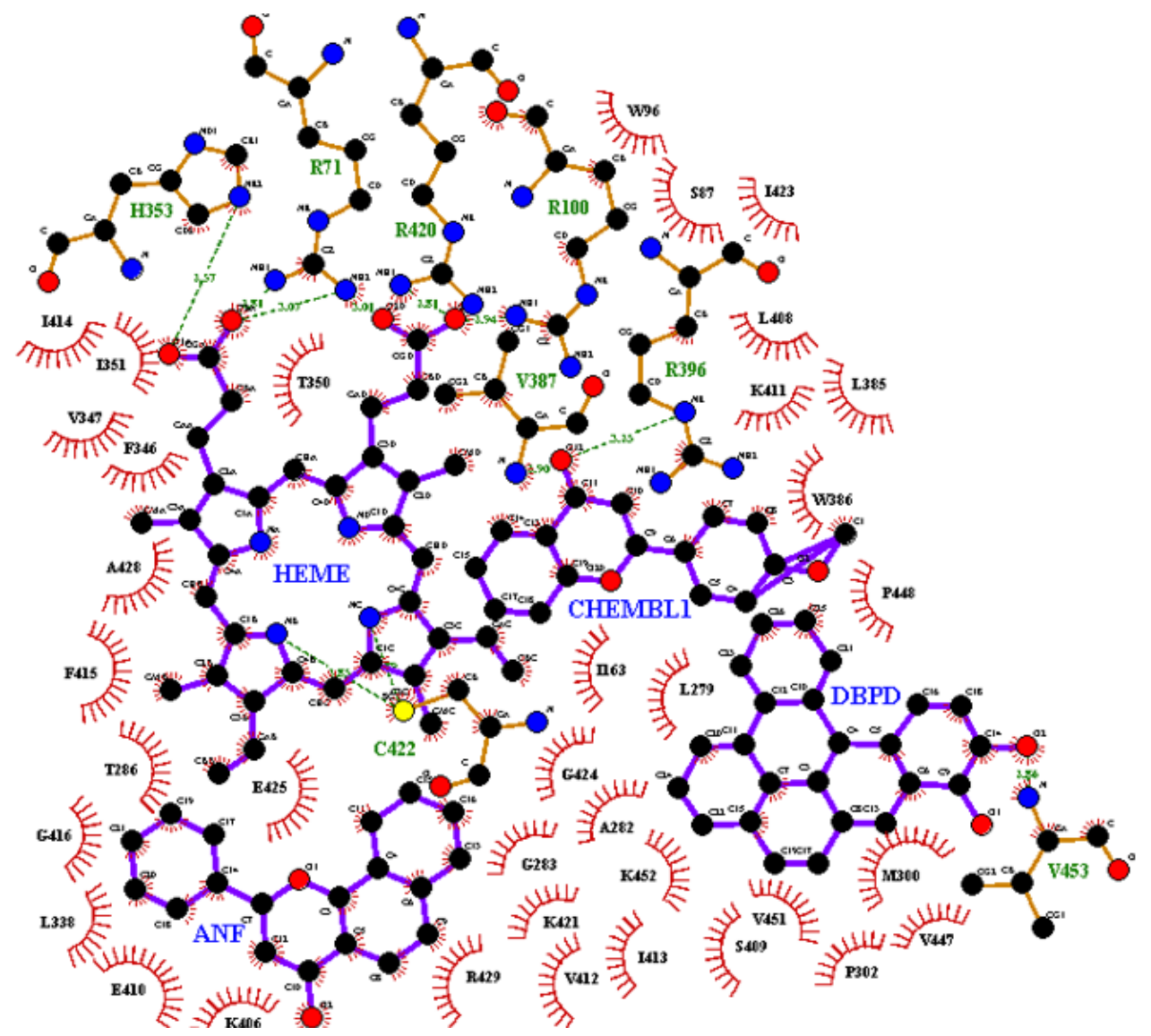

Figure 2. The 2D Ligplot of CYP1A1 with CHEMBL1, DBPD, and ANF. Dashed lines (green) and arcs, respectively, represent $\mathrm{H}$-bonds and hydrophobic contacts.

CHEMBL1 is also found more close to the heme group in comparison to DBPD and ANF. DBPD forms one H bond (V453-NH...O2-LIG), while hydrophobic residues are in close contact with ANF without any H-bond. Likewise, CHEMBL2 displayed strong interaction with CYP1A2 ( $\triangle \mathrm{G}:-10.82 \mathrm{kcal} / \mathrm{mol}$ ) with one H-bond (G14-NH...O5-LIG), making the docked complex stable. Moreover, it is also fitted to the cleft of heme compared to DBPD and ANF. One H-bond is also formed by each DBPD (A102-O...H42-LIG) and ANF (R263-NH...O1 LIG). The detailed illustration of CHEMBL2, DBPD, and ANF with CYP1A2 is given in Figure 3.

Similar to the CHEMBL1 and 2, CHEMBL3 interacted more efficiently to CYP1B1 ( $\Delta \mathrm{G}:-10.81 \mathrm{kcal} / \mathrm{mol}$ ), rendering the docked complex stable with one H-bond (N353-HE2 ...FLIG) formation. Additionally, it is also anchored near to heme, unlike DBPD and ANF. W354 and R263 form H-bond with respectively second and first oxygen of DBPD and ANF. Ten amino acid residues of CYP1B1, namely- arginine50, methionine65, threonine327, isoleucine328, glutamine353, isoleucine391, serine393, arginine397, cysteine399, and isoleucine400, exhibited significant interactions with both ligand CHEMBL3 and hemeconjugated ring system. The detailed molecular interaction of CHEMBL3, DBPD, and ANF with CYP1B1 is exemplified in Figure 4.

Most of the residues of CYP1B1 are showing similar interactions with its heme group and CHEMBL3, along with the substantial free energy of binding ( $\Delta \mathrm{G}:-10.81 \mathrm{kcal} / \mathrm{mol})$. CHEMBL2393069 also exhibited strong interaction having $-10.78 \mathrm{kcal} / \mathrm{mol}$ free energy of binding along with one H-bond formation (D255-OD2...H-LIG). Therefore, MDS of $50 \mathrm{~ns}$ for the complexes CYP1B1-CHEMBL3, CHEMBL2393069, DBPD, and known inhibitor ANF were executed to foresee the stability of docked molecules. 


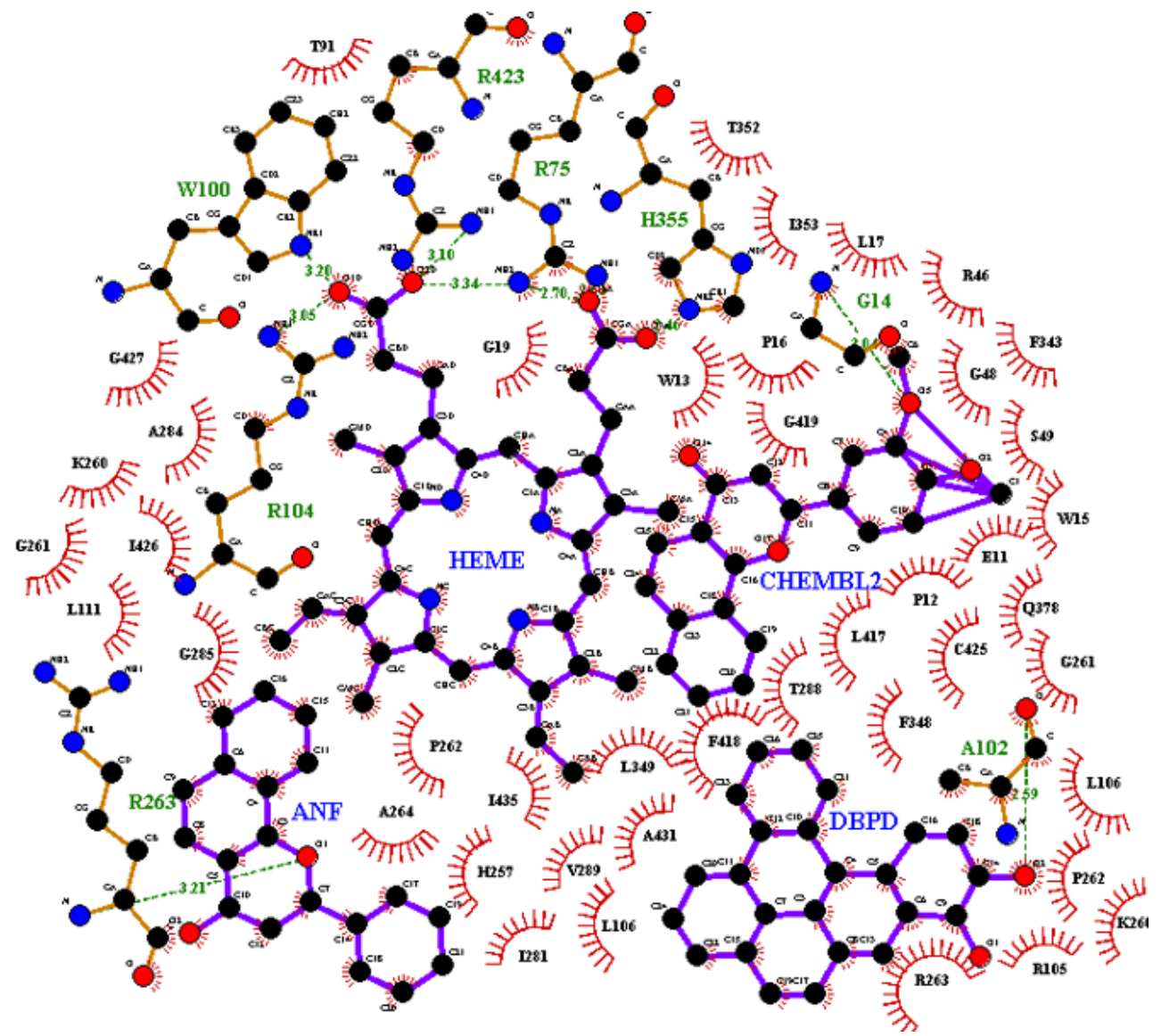

Figure 3. The 2D Ligplot of CYP1A2 with CHEMBL2, DBPD, and ANF. Dashed lines (green) and arcs, respectively, represent $\mathrm{H}$-bonds and hydrophobic contacts.

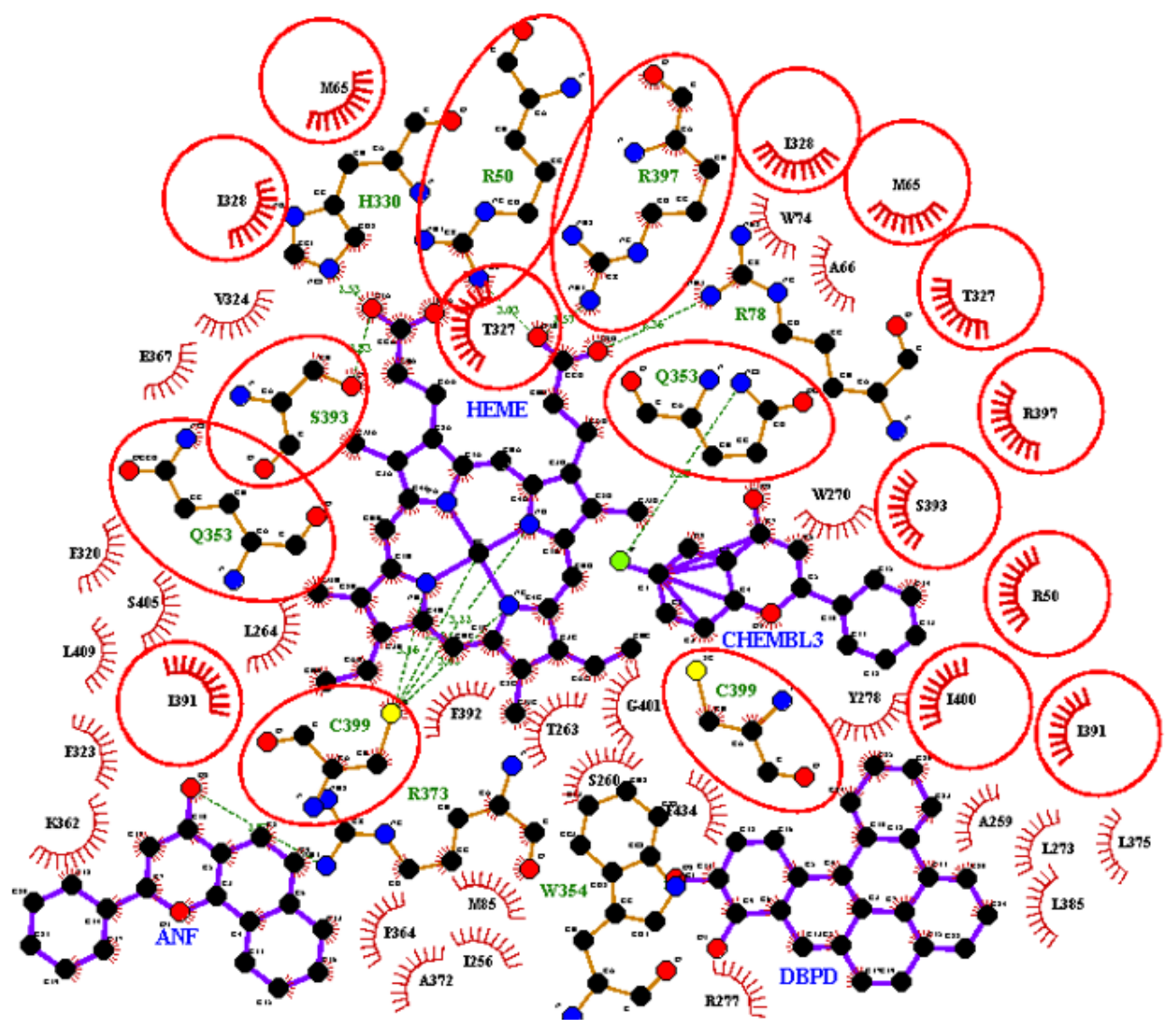

Figure 4. The 2D Ligplot of CYP1B1 with CHEMBL3, DBPD, and ANF. Dashed lines (green) and arcs, respectively, represent $\mathrm{H}$-bonds and hydrophobic contacts. Encircled residues are showing common interactions with the heme-conjugated ring system and ligand CHEMBL3. 
The root-mean-square deviation (RMSD) plot showcases ligands-protein docked complexes' stability [32]. The RMSD graph reveals that the CYP1B1-CHEMBL3 complex is in a more stable form, followed by CHEMBL2393069, ANF, and DBPD. The root-meansquare fluctuation (RMSF) aims to determine the stability of complexes during the entire timescale of MDS [33]. The solvent-accessible surface area (SASA) exposes the target protein's surface area accessible by the solvent molecule [34]. The RMSD, RMSF, and SASA plots favor the CYP1B1-CHEMBL3 complex's stability compared to CHEMBL2393069, DBPD, and ANF (Figure 5a-c).
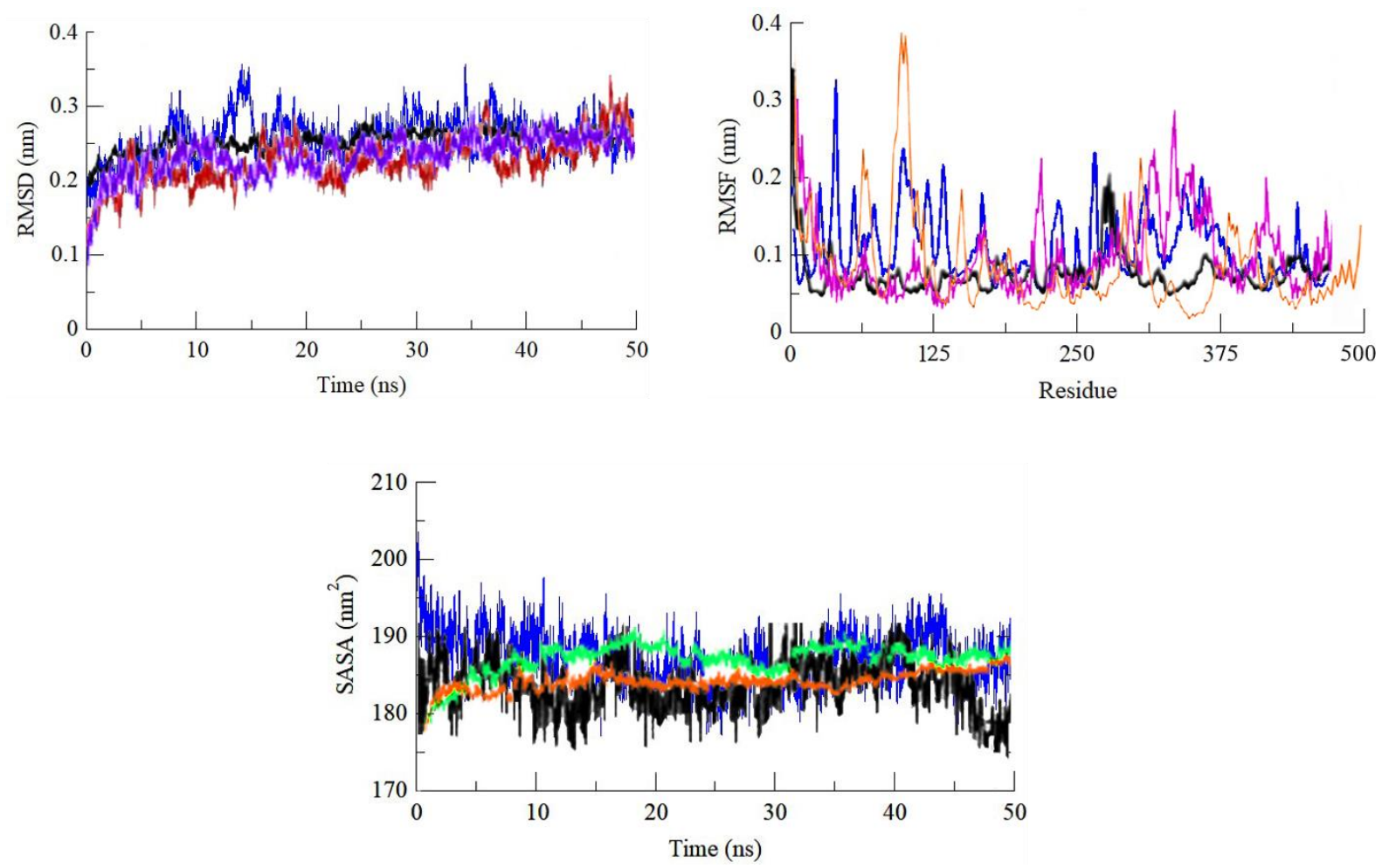

Figure 5. MD simulation of ligands binding to the CYP1B1 (a) RMSD plot as a function of time. Magenta, red, blue, and black colors represent CHEMBL3, CHEMBL2393069, DBPD, and ANF, respectively; (b) RMSF plot for CHEMBL3 (pink), CHEMBL2393069 (saffron), DBPD (blue), and ANF (black); (c) SASA plot for CHEMBL3 (green), CHEMBL2393069 (saffron), DBPD (blue), and ANF (black).

\subsection{MTT assay.}

The lead compounds CHEMBL1, 2, and 3 identified via in silico strategies were tested for their in vitro antiproliferative activity against the human breast cancer cell line MCF-7 at different concentrations $(0-100 \mu \mathrm{M})$ by MTT assay. The cell inhibition percentages of tested compounds were determined after measuring at 24 hours of exposure. The CHEMBL1 showed a 50\% cytotoxic effect on the MCF-7 cell line at $29.69 \mu \mathrm{M}$, and CHEMBL2 showed the cytotoxic effect at $13.56 \mu \mathrm{M}$, whereas CHEMBL3 showed 50\% cytotoxic effect on MCF-7 cell line at $8.36 \mu \mathrm{M}$ (Figure 6a-c). As shown in Figure 6a-c, compounds 1, 2, and 3 were found to inhibit the growth of breast cancer cell line MCF-7 potently, and its activity was significantly different from ANF at 25, 50, and $100 \mu \mathrm{M}$ doses [35-38]. Moreover, the MTT assay results suggested that CHEMBL3 was found to be the most potent against the MCF-7 cell line (Figure 6c) and could be probed further to delineate its strong anti-cancer potential. 

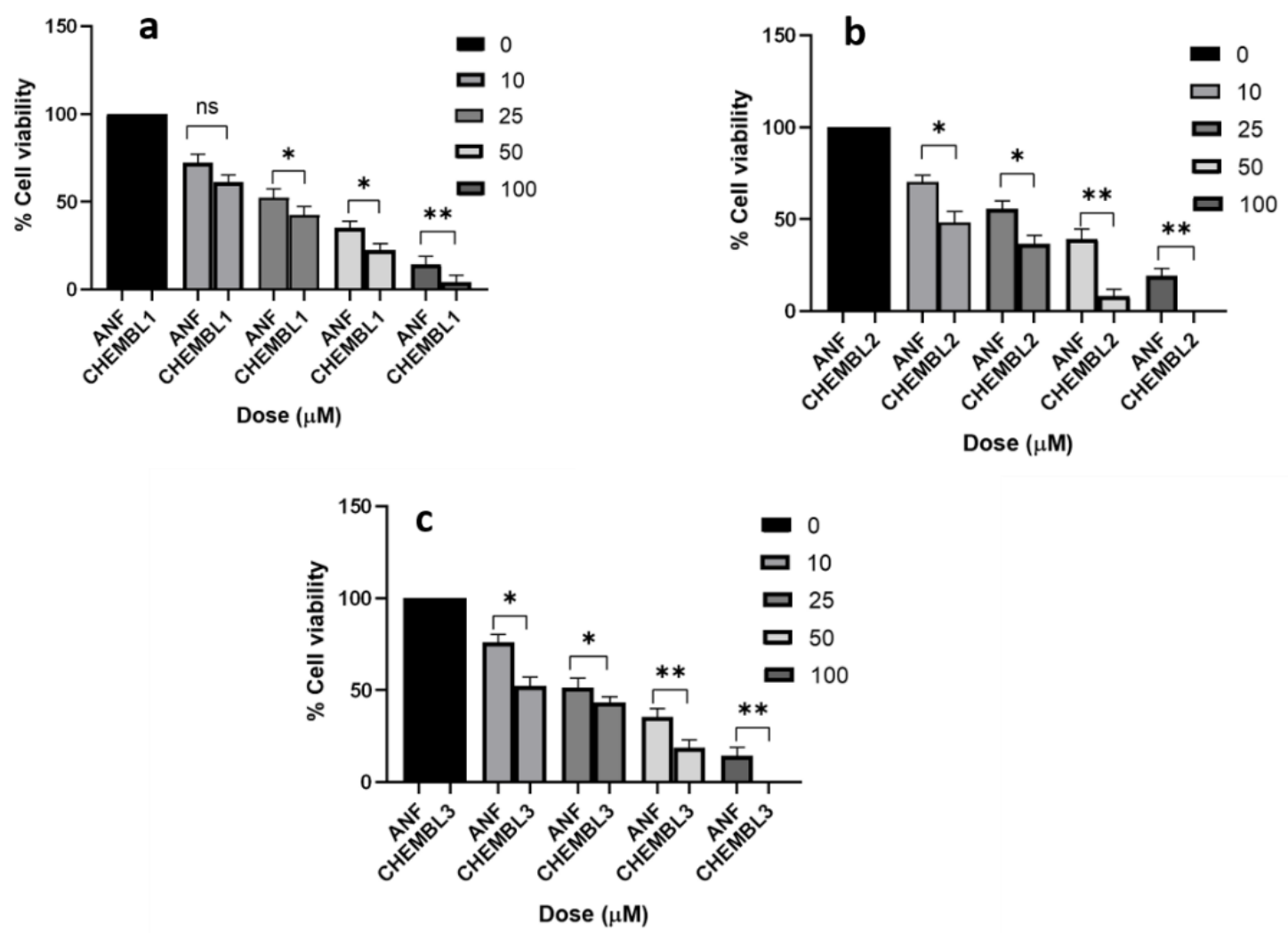

Figure 6. Dose-dependent inhibition of cell viability of breast cancer cell line MCF-7 by alpha-naphthoflavone

(ANF) and (a) CHEMBL1; (b) CHEMBL2; (c) CHEMBL3. The data is Mean \pm SD of three independent experiments repeated thrice $(* \mathrm{p}<0.01, * * \mathrm{p}<0.001$ were considered significant; ns represents non-significant).
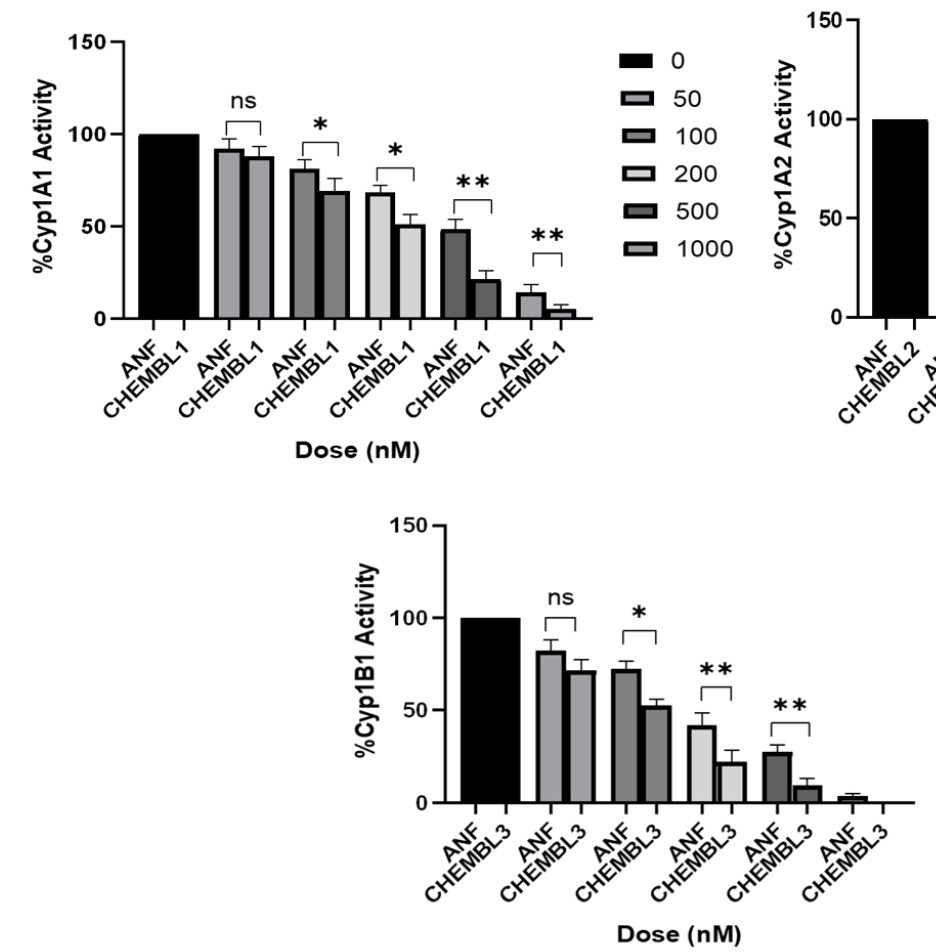

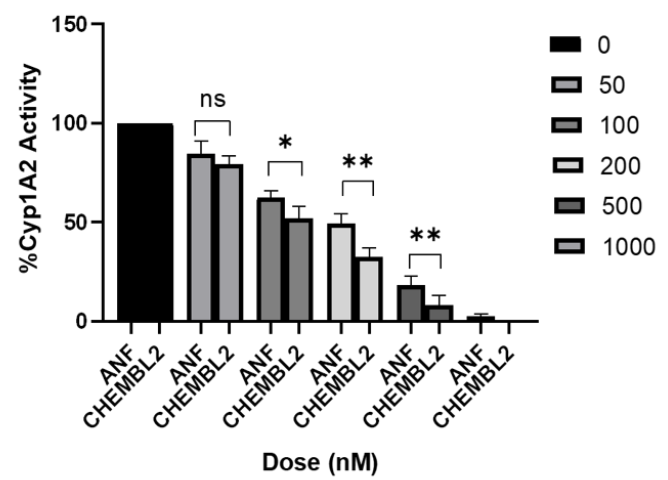

= 0

50

ㅁ 100

ㅁ 200

口 500

口 1000

Figure 7. Enzyme inhibition activity in breast cancer cell line MCF-7 (a) CYP1A1 by CHEMBL1, (b) CYP1A2 by CHEMBL2, and (c) CYP1B1 by CHEMBL3. The ANF was taken as a known inhibitor of CYP1A1, 1A2, and $1 \mathrm{~B} 1$ isozymes. The data is Mean $\pm \mathrm{SD}$ of three independent experiments repeated thrice $\left({ }^{*} \mathrm{p}<0.01, * * \mathrm{p}<0.001\right.$ were considered significant; ns represents non-significant). 


\subsection{Enzyme inhibition assay.}

The inhibition of various CYP enzyme activity by CHEMBL1, 2, and 3 were measured using a specific substrate described in Materials and Methods. Our results have shown that CHEMBL1, 2, and 3 inhibited CYP1A1, CYP1A2, and CYP1B1 enzyme activity in a dose-dependent manner [39,40]. CHEMBL1 (50-1000 nM) significantly inhibited CYP1A1 activity, and the inhibition was significantly different from ANF, a known CYP1A1 inhibitor, at 100, 200, and $500 \mathrm{nM}$ doses. Similarly, CHEMBL2 (50-1000 nM) showed potent inhibition of CYP1A2 activity, and the reduction in the activity was significantly different from ANF at 100, 200, and 500nM doses. Moreover, CHEMBL3 (50-1000 nM) potently inhibited the CYP1B1 activity, and the inhibition was significantly different from ANF at 100, 200, and 500 $\mathrm{nM}$ doses. Therefore, our results suggest that inhibition of CYP1A1, CYP1A2, and CYP1B1 enzymes by our proposed compounds could prevent DBP-induced mammary cancer because of suppression of carcinogenic activation of DBP (Figure 7a-c).

\section{Conclusions}

AhR and its other associated proteins facilitate the biotransformation of DBP, as shown in Figure 3. CHEMBL1 (6-iodo-4'-methoxyflavone), CHEMBL2 (3',4'-dimethoxy-alphanaphthoflavone), and CHEMBL3 (6-fluoroflavone) exhibited better molecular interactions with CYP1A1, CYP1A2, and CYP1B1, respectively, as shown by in silico findings viz., molecular docking and MD simulation analysis. These compounds were found docked into the binding pocket of their respective targets with excellent binding pattern and orientation, thereby establishing strong bonded and non-bonded molecular interactions compared to DBPD and ANF. The proximity of lead molecules near the heme-ring system's cleft might disturb the consensus motif signature of selected metabolizing enzymes, thus inhibiting the formation of carcinogenic metabolites. Moreover, in vitro experiments, including MTT and enzyme inhibition assays, validate and elucidate the structural mechanistic perspectives of CHEMBL1, 2, and 3. Thus, these compounds having potential inhibition properties might be used as promising lead molecules against CYP1A1, 1A2, and 1B1 isozymes.

\section{Funding}

This research received no external funding.

\section{Acknowledgments}

The authors acknowledge the Integral University gratefully for providing the infrastructural facilities to carry out this research (IU/R\&D/2021-MCN0001110).

\section{Conflicts of Interest}

The authors declare no conflict of interest.

\section{References}

1. Anifowose, A. J.; Ogundola, A. O.; Babalola, B. M.; Awojide, S. H. Measurement, Source-Profiling and Potential Toxicity of Polycyclic Aromatic Hydrocarbons in an Agrarian Soil. Environ. Process. 2020, 7, 827844, https://doi.org/10.1007/s40710-020-00446-3. 
2. Jeffery, J.; Carradus, M.; Songin, K.; Pettit, M.; Pettit, K.; Wright, C. Optimized Method for Determination of 16 FDA Polycyclic Aromatic Hydrocarbons (PAHs) in Mainstream Cigarette Smoke by Gas Chromatography-Mass Spectrometry. Chem. Cent. J. 2018, 12, 27, https://doi.org/10.1186/s13065-0180397-2.

3. Khan, M. K. A.; Akhtar, S.; Arif, J. M. Development of In Silico Protocols to Predict Structural Insights into the Metabolic Activation Pathways of Xenobiotics. Interdiscip. Sci. 2018, 10, 329-345, https://doi.org/10.1007/s12539-017-0237-4.

4. Khan, M. K. A.; Akhtar, S.; Arif, J. M. Structural Insight into the Mechanism of Dibenzo[a,1]Pyrene and Benzo[a]Pyrene-Mediated Cell Proliferation Using Molecular Docking Simulations. Interdiscip. Sci. 2018, 10, 653-673. https://doi.org/10.1007/s12539-017-0226-7.

5. Luch, A.; Schober, W.; Soballa, V. J.; Raab, G.; Greim, H.; Jacob, J.; Doehmer, J.; Seidel, A. Metabolic Activation of Dibenzo[a,1]Pyrene by Human Cytochrome P450 1A1 and P450 1B1 Expressed in V79 Chinese Hamster Cells. Chem. Res. Toxicol. 1999, 12, 353-364, https://doi.org/10.1021/tx980240g.

6. Smith, J. N.; Mehinagic, D.; Nag, S.; Crowell, S. R.; Corley, R. A. In vitro Metabolism of Benzo[a]Pyrene7,8-Dihydrodiol and Dibenzo[Def,p]Chrysene-11,12 Diol in Rodent and Human Hepatic Microsomes. Toxicol. Lett. 2017, 269, 23-32, https://doi.org/10.1016/j.toxlet.2017.01.008.

7. Shimada, T. Inhibition of Carcinogen-Activating Cytochrome P450 Enzymes by Xenobiotic Chemicals in Relation to Antimutagenicity and Anticarcinogenicity. Toxicol. Res. 2017, 33, 79-96, https://doi.org/10.5487/TR.2017.33.2.079.

8. Siddens, L. K.; Larkin, A.; Krueger, S. K.; Bradfield, C. A.; Waters, K. M.; Tilton, S. C.; Pereira, C. B.; Löhr, C. V.; Arlt, V. M.; Phillips, D. H.; Williams, D. E.; Baird, W. M. Polycyclic Aromatic Hydrocarbons as Skin Carcinogens: Comparison of Benzo[a]Pyrene, Dibenzo[Def,p]Chrysene and Three Environmental Mixtures in the FVB/N Mouse. Toxicol. Appl. Pharmacol. 2012, 264, 377-386, https://doi.org/10.1016/j.taap.2012.08.014.

9. Manikandan, P.; Nagini, S. Cytochrome P450 Structure, Function and Clinical Significance: A Review. Curr. Drug Targets 2018, 19, https://doi.org/10.2174/1389450118666170125144557.

10. Munro, A. W.; McLean, K. J.; Grant, J. L.; Makris, T. M. Structure and Function of the Cytochrome P450 Peroxygenase Enzymes. Biochem. Soc. Trans. 2018, 46, 183-196, https://doi.org/10.1042/BST20170218.

11. Barnaba, C.; Gentry, K.; Sumangala, N.; Ramamoorthy, A. The Catalytic Function of Cytochrome P450 Is Entwined with Its Membrane-Bound Nature. F1000Research 2017, 6, 662, https://doi.org/10.12688/f1000research.11015.1.

12. Rendic, S. P.; Guengerich, F. P. Human Family 1-4 Cytochrome P450 Enzymes Involved in the Metabolic Activation of Xenobiotic and Physiological Chemicals: An Update. Arch. Toxicol. 2021, 95, 395-472, https://doi.org/10.1007/s00204-020-02971-4.

13. Nakano, N.; Sakata, N.; Katsu, Y.; Nochise, D.; Sato, E.; Takahashi, Y.; Yamaguchi, S.; Haga, Y.; Ikeno, S.; Motizuki, M.; Sano, K.; Yamasaki, K.; Miyazawa, K.; Itoh, S. Dissociation of the AhR/ARNT Complex by TGF- $\beta$ /Smad Signaling Represses CYP1A1 Gene Expression and Inhibits Benze[a]Pyrene-Mediated Cytotoxicity. J. Biol. Chem. 2020, 295, 9033-9051, https://doi.org/10.1074/jbc.RA120.013596.

14. Androutsopoulos, V. P.; Tsatsakis, A. M.; Spandidos, D. A. Cytochrome P450 CYP1A1: Wider Roles in Cancer Progression and Prevention. BMC Cancer 2009, 9, 187, https://doi.org/10.1186/1471-2407-9-187.

15. Lemkul, J. A. Pairwise-Additive and Polarizable Atomistic Force Fields for Molecular Dynamics Simulations of Proteins. In Progress in Molecular Biology and Translational Science; 2020; 1-71, https://doi.org/10.1016/bs.pmbts.2019.12.009.

16. Kim, S.; Lee, J.; Jo, S.; Brooks, C. L.; Lee, H. S.; Im, W. CHARMM-GUI Ligand Reader and Modeler for CHARMM Force Field Generation of Small Molecules. J. Comput. Chem. 2017, 38, 1879-1886, https://doi.org/10.1002/jcc.24829.

17. Van Den Driessche, G.; Fourches, D. Adverse Drug Reactions Triggered by the Common HLA-B*57:01 Variant: Virtual Screening of DrugBank Using 3D Molecular Docking. J. Cheminform. 2018, 10, 3, https://doi.org/10.1186/s13321-018-0257-z.

18. Zoete, V.; Daina, A.; Bovigny, C.; Michielin, O. SwissSimilarity: A Web Tool for Low to Ultra High Throughput Ligand-Based Virtual Screening. J. Chem. Inf. Model. 2016, 56, 1399-1404, https://doi.org/10.1021/acs.jcim.6b00174.

19. Lipinski, C. A. Lead- and Drug-like Compounds: The Rule-of-Five Revolution. Drug Discov. Today Technol. 2004, 1, 337-341, https://doi.org/10.1016/j.ddtec.2004.11.007. 
20. Tan, H.-Y.; Trier, S.; Rahbek, U. L.; Dufva, M.; Kutter, J. P.; Andresen, T. L. A Multi-Chamber Microfluidic Intestinal Barrier Model Using Caco-2 Cells for Drug Transport Studies. PLoS One 2018, 13, e0197101. https://doi.org/10.1371/journal.pone.0197101.

21. Zhu, J.; Yi, X.; Zhang, J.; Chen, S.; Wu, Y. Rapid Screening of Brain-Penetrable Antioxidants from Natural Products by Blood-Brain Barrier Specific Permeability Assay Combined with DPPH Recognition. J. Pharm. Biomed. Anal. 2018, 151, 42-48, https://doi.org/10.1016/j.jpba.2017.12.055.

22. Liu, W.; Jiang, X.; Zu, Y.; Yang, Y.; Liu, Y.; Sun, X.; Xu, Z.; Ding, H.; Zhao, Q. A Comprehensive Description of GluN2B-Selective N-Methyl-D-Aspartate (NMDA) Receptor Antagonists. Eur. J. Med. Chem. 2020, 200, 112447. https://doi.org/10.1016/j.ejmech.2020.112447.

23. Morris, G. M.; Goodsell, D. S.; Halliday, R. S.; Huey, R.; Hart, W. E.; Belew, R. K.; Olson, A. J. Automated Docking Using a Lamarckian Genetic Algorithm and an Empirical Binding Free Energy Function. J. Comput. Chem. 1998, 19, 1639-1662. https://doi.org/10.1002/(SICI)1096-987X(19981115)19:14<1639::AIDJCC10>3.0.CO;2-B.

24. Morris, G. M.; Goodsell, D. S.; Huey, R.; Olson, A. J. Distributed Automated Docking of Flexible Ligands to Proteins: Parallel Applications of AutoDock 2.4. J. Comput. Aided. Mol. Des. 1996, 10, 293-304, https://doi.org/10.1007/BF00124499.

25. Khan, F. I.; Lai, D.; Anwer, R.; Azim, I.; Khan, M. K. A. Identifying Novel Sphingosine Kinase 1 Inhibitors as Therapeutics against Breast Cancer. J. Enzyme Inhib. Med. Chem. 2020, 35, 172-186, https://doi.org/10.1080/14756366.2019.1692828.

26. Khan, S.; Khan, F. I.; Mohammad, T.; Khan, P.; Hasan, G. M.; Lobb, K. A.; Islam, A.; Ahmad, F.; Imtaiyaz Hassan, M. Exploring Molecular Insights into the Interaction Mechanism of Cholesterol Derivatives with the Mce4A: A Combined Spectroscopic and Molecular Dynamic Simulation Studies. Int. J. Biol. Macromol. 2018, 111, 548-560, https://doi.org/10.1016/j.ijbiomac.2017.12.160.

27. Gunasekaran, D.; Sridhar, J.; Suryanarayanan, V.; Manimaran, N. C.; Singh, S. K. Molecular Modeling and Structural Analysis of NAChR Variants Uncovers the Mechanism of Resistance to Snake Toxins. J. Biomol. Struct. Dyn. 2017, 35, 1654-1671. https://doi.org/10.1080/07391102.2016.1190791.

28. Naz, F.; Khan, F. I.; Mohammad, T.; Khan, P.; Manzoor, S.; Hasan, G. M.; Lobb, K. A.; Luqman, S.; Islam, A.; Ahmad, F.; Hassan, M. I. Investigation of Molecular Mechanism of Recognition between Citral and MARK4: A Newer Therapeutic Approach to Attenuate Cancer Cell Progression. Int. J. Biol. Macromol. 2018, 107 (Pt B), 2580-2589. https://doi.org/10.1016/j.ijbiomac.2017.10.143.

29. Mosmann, T. Rapid Colorimetric Assay for Cellular Growth and Survival: Application to Proliferation and Cytotoxicity Assays. J. Immunol. Methods 1983, 65, 55-63, https://doi.org/10.1016/0022-1759(83)90303-4.

30. Alreshidi, F. S.; Ginawi, I. A.; Hussain, M. A.; Arif, J. M. Piperaquine- and Aspirin- Mediated Protective Role of HSP70 and HSP90 as Modes to Strengthen the Natural Immunity against Potent SARS-CoV-2. Biointerface Res. Appl. Chem. 2021, 11, 12364-12379, https://doi.org/10.33263/BRIAC114.1236412379.

31. Laskowski, R. A.; Swindells, M. B. LigPlot+: Multiple Ligand-Protein Interaction Diagrams for Drug Discovery. J. Chem. Inf. Model. 2011, 51, 2778-2786, https://doi.org/10.1021/ci200227u.

32. Baildya, N.; Khan, A. A.; Ghosh, N. N.; Dutta, T.; Chattopadhyay, A. P. Screening of Potential Drug from Azadirachta Indica (Neem) Extracts for SARS-CoV-2: An Insight from Molecular Docking and MDSimulation Studies. J. Mol. Struct. 2021, 1227, https://doi.org/10.1016/j.molstruc.2020.129390.

33. Naz, S.; Farooq, U.; Khan, S.; Sarwar, R.; Mabkhot, Y. N.; Saeed, M.; Alsayari, A.; Muhsinah, A. Bin; UlHaq, Z. Pharmacophore Model-Based Virtual Screening, Docking, Biological Evaluation and Molecular Dynamics Simulations for Inhibitors Discovery against $\alpha$-Tryptophan Synthase from Mycobacterium Tuberculosis. J. Biomol. Struct. Dyn. 2021, 39, https://doi.org/10.1080/07391102.2020.1715259.

34. Taghvaei, S.; Sabouni, F.; Minuchehr, Z.; Taghvaei, A. Identification of Novel Anti-Cancer Agents, Applying in Silico Method for SENP1 Protease Inhibition. J. Biomol. Struct. Dyn. 2021, https://doi.org/10.1080/07391102.2021.1880480.

35. Datta, A.; Bhasin, N.; Kim, H.; Ranjan, M.; Rider, B.; Abd Elmageed, Z. Y.; Mondal, D.; Agrawal, K. C.; Abdel-Mageed, A. B. Selective Targeting of FAK-Pyk2 Axis by Alpha-Naphthoflavone Abrogates Doxorubicin Resistance in Breast Cancer Cells. Cancer Lett. 2015, 362, 25-35, https://doi.org/10.1016/j.canlet.2015.03.009.

36. Osmaniye, D.; Korkut Çelikateş, B.; Sağlık, B. N.; Levent, S.; Acar Çevik, U.; Kaya Çavuşoğlu, B.; Ilgın, S.; Özkay, Y.; Kaplancıklı, Z. A. Synthesis of Some New Benzoxazole Derivatives and Investigation of Their Anticancer Activities. Eur. J. Med. Chem. 2021, 210, 112979, https://doi.org/10.1016/j.ejmech.2020.112979. 
37. Surichan, S.; Arroo, R. R.; Tsatsakis, A. M.; Androutsopoulos, V. P. Tangeretin Inhibits the Proliferation of Human Breast Cancer Cells via CYP1A1/CYP1B1 Enzyme Induction and CYP1A1/CYP1B1-Mediated Metabolism to the Product 4' Hydroxy Tangeretin. Toxicol. Vitr. 2018, 50, 274-284, https://doi.org/10.1016/j.tiv.2018.04.001.

38. Wójcikowski, J.; Danek, P. J.; Basińska-Ziobroń, A.; Pukło, R.; Daniel, W. A. In Vitro Inhibition of Human Cytochrome P450 Enzymes by the Novel Atypical Antipsychotic Drug Asenapine: A Prediction of Possible Drug-Drug Interactions. Pharmacol. Reports 2020, 72, 612-621, https://doi.org/10.1007/s43440-020-00089z.

39. Shimada, T.; Guengerich, F. P. Inhibition of Human Cytochrome P450 1A1-, 1A2-, and 1B1-Mediated Activation of Procarcinogens to Genotoxic Metabolites by Polycyclic Aromatic Hydrocarbons. Chem. Res. Toxicol. 2006, 19, https://doi.org/10.1021/tx050291v.

40. Juvonen, R. O.; Jokinen, E. M.; Javaid, A.; Lehtonen, M.; Raunio, H.; Pentikäinen, O. T. Inhibition of Human CYP1 Enzymes by a Classical Inhibitor A-naphthoflavone and a Novel Inhibitor N -(3, 5dichlorophenyl)Cyclopropanecarboxamide: An in Vitro and in Silico Study. Chem. Biol. Drug Des. 2020, 95 , 520-533, https://doi.org/10.1111/cbdd.13669. 